\title{
Restorying for transdisciplinarity: A proposed teaching-learning strategy in a context of Human Rights Education
}

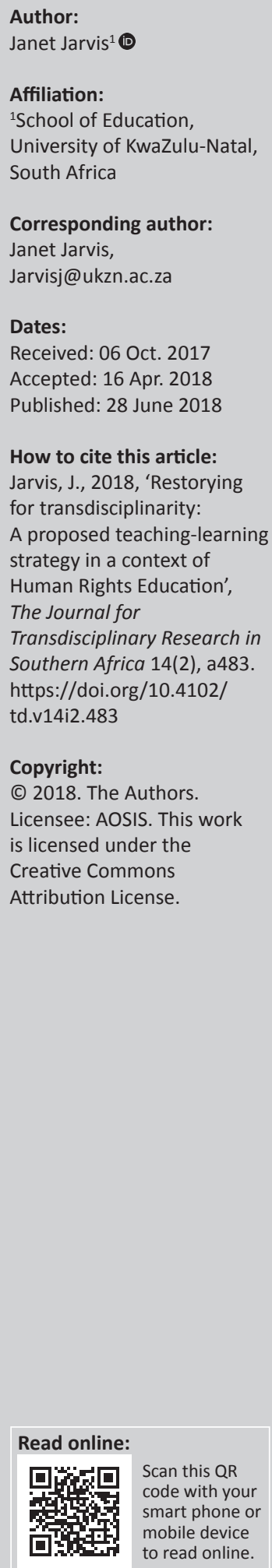

Human Rights Education can provide a context for transdisciplinary boundary talk as a possible way to create cohesion among the multiple disciplines embedded within the Social Sciences. This article presents a teaching-learning strategy, Empathetic-Reflective-Dialogical Restorying, which can be employed to facilitate such boundary talk. Both self-dialogue and self-narrative are used to create open space stories. This provides a platform for restorying as Social Science postgraduate students at a South African higher education institution engage in the space between, across and beyond academic disciplines. Conversation centres on the human right to gender equality as informed by the individual's substantial and situational identities. The teaching-learning strategy introducing as it does, communities in conversation, communities in dialogue and communities for transformation, can be used to create possible cohesion among both academics and students in the Social Sciences. It also has the potential to be transformative beyond the Social Sciences and indeed, society at large.

\section{Introduction}

Human Rights Education research has been criticised for being 'predominantly school-based and fundamentally descriptive and uncritical' (Simmonds \& Du Preez 2017:17). In this article, this conventional approach to Human Rights Education ${ }^{1}$ is troubled and human rights issues and in particular, the human right to gender equality as it is embedded in the South African Constitution (Bill of Rights) (Republic of South Africa 1996) is employed to facilitate transdisciplinary boundary talk in a higher education institution with a view to possibly being a catalyst for social transformation. Human rights issues are embedded in the Policy of Human Rights across the Curriculum (Department of Education 2003) and the teaching-learning of democratic values as outlined in the Manifesto of Values, Education and Democracy (Department of Education 2001). Human Rights Education can cut between, across and beyond academic discipline boundaries, interrogating as it does human rights issues, drawing on social intersectionality (Crenshaw 2003; Shields 2008) and affecting as it does the whole teaching-learning space (Jacobs, Vakalisa \& Gawe 2011). Central to any human rights conversation is the individual's substantial (personal) and situational (professional) identities (Nias 1989). According to Roux (2012:41), 'teachers cannot mediate or facilitate knowledge and skills pertaining to human rights without understanding their own position, identity and beliefs'.

Transdisciplinarity has been hailed as a powerful tool for 'ensuring the empowerment of higher education to be a catalysing force for social transformation through direct, continuous engagement in communities ...' (Hampson \& Assenza 2012:6-7). In this article, transdisciplinary boundary talk (Godemann 2006) and more specifically Empathetic-Reflective-Dialogical Restorying as a teaching-learning strategy is presented, requiring students to engage with their substantial as well as situational identities. Drawing on self-dialogue and self-narrative, Empathetic-ReflectiveDialogical Restorying has the potential to facilitate transdisciplinary boundary talk and to transform classroom practice into praxis (McCormack \& Kennelly 2011).

An empathetic approach refers to the capacity of individuals to understand and to respond to their other with an increased awareness of their other's thoughts and feelings (Abdool \& Drinkwater 2005). Engaging in reflection entails the examination of responses, beliefs and premises which could result in the integration of new understandings into experience (McCormack \& Kennelly 2011). Dialogue refers to the search for meaning and understanding. It necessitates engaging with others, recognising that each person has something of value to contribute 
(Allen 2004). It is about opening up to the possibility of learning from the other (Ipgrave 2003). Empathetically engaging in dialogue with others and then reflecting on this engagement can lead to restorying, namely the revising of an existing narrative, as new interpretations or clarified understandings are applied to dominant discourses.

Empathetic-Reflective-Dialogical Restorying facilitates transdisciplinary boundary talk exploring how the substantial and situational identities of Social Sciences students intersect, in this case, with the human right to gender equality. Gender equality refers to men and women being equal in dignity and in terms of their shared humanity, having identical value or worth and enjoying the same rights and opportunities (Subrahmanian 2005).

This teaching-learning strategy provides students with the opportunity to reflectively engage with their own perspectives by way of self-dialogue and then to express this through selfnarrative. They are also provided with the opportunity to empathetically search for meaning and understanding of perspectives which are different from their own as they engage in communities in conversation $(\mathrm{CiC})$ (De Wet \& Parker 2014; Roux 2012) and communities in dialogue(CiD) (Roux 2012). This has the potential to be both emancipatory and transformational as they engage in boundary talk.

The difficulties encountered at disciplinary boundaries, or border troubles (Petts, Owens \& Bulkeley 2006), involve the epistemological structuring of disciplines and the privileging of certain frames of enquiry and methodological approaches.

While multidisciplinarity involves a number of different disciplines coming together, each disciplinary group works primarily with its own framings and methods (in the case of this study, each of the nine disciplines fall within the Social Sciences cluster) (Nicolescu 2014). Gender equality as a human right can be studied from a multidisciplinary perspective within the Social Sciences, embracing, for example Social Justice Education, Gender and Education and Religion Education as it falls within Life Orientation Education. A discussion about gender equality will be enriched by incorporating the perspectives of several disciplines. However, this multidisciplinary approach, while overflowing disciplinary boundaries, has 'its goal remaining limited to the framework of disciplinary research' (Nicolescu 2005:5).

Another approach to boundary talk would be that of interdisciplinarity which refers to a synthesis of knowledge, drawn from more than one discipline, in which understandings change in response to the perspectives of others. According to Nicolescu (2014:187), 'it concerns the transfer of methods from one discipline to another ... but its goal still remains within the framework of disciplinary research ...' Interdisciplinarity does not constitute meaningful boundary talk.

By contrast, transdisciplinary engagement, transcending disciplinary boundaries, strives to solve problems (McGregor
\& Volckmann 2013) by generating new transdisciplinary knowledges (Nicolescu 2005) in the space between, across and beyond academic disciplines (McGregor \& Volckmann 2013; Nicolescu 2005; 2014).

Graduate programmes enabling students to engage in transdisciplinary boundary talk have the potential to contribute to the creation of new knowledges and understandings which, in turn, have the potential to be socially transformative.

This article draws on the findings of a small-scale project located at a South African university in the College of Humanities and more specifically the cluster of Social Sciences Education in the School of Education. The specific disciplines located within this cluster include Commerce Education, Gender and Education, Geography Education, History Education, Life Orientation Education, Social Science Education, Social Justice Education, Sports Science Education and Travel and Tourism Education. The project endeavoured to create cohesion among these disciplines which fall under the historically designed umbrella of the Social Sciences. Transdisciplinary boundary talk required the researcher and the students to find a way of communicating across disciplinary boundaries. This transdisciplinary boundary talk was facilitated by Empathetic-ReflectiveDialogical Restorying with the human right to gender equality as the focus of conversation in which 24 Social Sciences postgraduate students, embedded in their particular disciplines participated.

For this Empathetic-Reflective-Dialogical Restorying to be effective, a safe space (Du Preez \& Simmonds 2011; Roux 2012) was created where substantial and situational identities could intersect. This safe space does not only refer to literal or physical safety but rather denotes the figurative and discursive use of the notion (Du Preez 2013; Redmond 2010; Stengel \& Weems 2010). Despite possible discomfort, these spaces are safe because they are the place where, in relation to this teaching-learning strategy, Social Sciences students engaged in a $\mathrm{CiC}$, a $\mathrm{CiD}$ and a community for transformation (CfT). According to Nicolescu $(2014: 187,195)$, this transdisciplinary border talk can be described as 'a fertile complementarity', embracing complexity because 'transdisciplinary knowledge transgresses duality'.

Nicolescu's (2012) theory of the Included Middle conceives 'of people moving to a place where they become open to others' perspectives ... valu[ing] premises and belief systems ... letting go of aspects of how they currently know the world' (McGregor 2011; McGregor \& Volckmann 2013:62). The logic of the Included Middle requires the creation of a space for dialogue and knowledge generation. That is what the teaching-learning strategy presented in this article facilitates, engaging as it does with students from different disciplines who, when they come into contact with each other, are energised. In this case, as the students engage with Human Rights Education issues related to gender equality, the strength and potentialities that emerge from these 
intellectual encounters have the potential to be transformative (McGregor \& Volckmann 2013).

\section{Theoretical framework underpinning Empathetic- Reflective-Dialogical Restorying}

The following bricolage provides the framework for Empathetic-Reflective-Dialogical Restorying. These theories were employed in a recent study (Jarvis 2013).

The dialogical self provides a link between self and society. Hermans' (2011) Dialogical Self Theory advocates that individuals live not only in external spaces but also in the internal space of their society-of-mind. Possible identity recreation can result from the dialogical self in action. This occurs when the individual moves from one $I$ position to another in the self as a way of gaining understanding about the self in relation to the world (Hermans \& HermansKonopka 2010). An example of this, when engaging with the human right to gender equality, would be the adoption of a counter-position to both individual and collective dominant voices in the individual's society-of-mind that promote male hegemony. This self-dialogue can inform self-narrative.

Various scholars (Gonçalves \& Ribeiro 2012; Nothling 2001; Nuttall 2009; White 2012) make the link between narrative and agency, arguing that self-narration can help individuals to make sense of their lives, past and present. Self-narrative has a role to play in enabling individuals to discover the degree to which they are entangled with their other (in this case, men or women) and, furthermore, the extent to which it might be possible to become disentangled from their other (men or women) and thus be freed to build new identities (Nuttall 2009). In this sense, the self-narrative can be emancipatory and empowering as it can fragment and reinterpret dominant discourses such as that of male hegemony (Lawler 2008).

It is the contention of Ter Avest (2011) that self-narratives which have the greatest potential to transform readers are open space stories. Such stories, instead of trying to colonise readers, allow them sufficient space to deconstruct and reconstruct what they receive. The possibility then presents itself that as students engage in open conversations they might restory what they know (revise their narrative), as new interpretations are applied in the light of clarified or new understandings of dominant discourses. This can potentially lead to the co-production of new knowledge as individuals previously locked into their traditions, embark upon personal journeys of restorying. In this project, the restorying takes place in and through the following conversations:

\section{Community in conversation}

A community in conversation (De Wet \& Parker 2014; Roux 2012) provides the opportunity for an informal sharing of information in conversation in a safe space. In the case of gender equality, for example men and women meet separately. This conversation Green (1999) refers to as negotiation and collaboration. Informally exchanging perspectives and personal experiences can foster respect, trust and tolerant understanding as 'divergent ways of thinking and speaking' (McCormack \& Kennelly 2011:522) are reflected upon. This reflection entails the examination of responses, beliefs and premises, resulting in the integration of new understandings into experience (McCormack \& Kennelly 2011). This process of reflection is very relevant within a $\mathrm{CiC}$ where it is anticipated that as men and women separately but reciprocally share their self-narratives they will reflect on the position of men and women (and their others) in, for example their religious and cultural discourses. Their intersection with other organising principles in society (Wetherell 1996) could also be considered.

\section{Community in dialogue}

A community in dialogue (Roux 2012) fosters the opportunity in which the other is disclosed to their other (women or men) in a dialogue which includes a rhetoric that questions and a rhetoric that reveals respect, and inspires reciprocal exchanges with tolerant and empathetic understanding and collaboration initiatives for transformation. Conversations could be designed around unpacking the implications of gender equality as expressed in the Bill of Rights (Republic of South Africa 1996). The aim of the CiD would be to understand self-respect and own positionality and inspire reciprocal exchanges with empathetic understanding. This dialogue has the potential to lead to a conversation in a CfT.

\section{Community for transformation}

A community for transformation aims to explore how, in this case, new knowledge about substantial and situational identities and the human right to gender equality could inform teaching-learning about human rights for transformative classroom praxis. The CfT could identify challenges and possibilities for constructive engagement that could lead to new layers of consciousness (White 2012) which has the potential to lead to action.

Self-dialogue (to an internal audience) is expressed as selfnarrative (to an external audience) in the spaces created by a $\mathrm{CiC}, \mathrm{CiD}$ and CfT. Transdisciplinary boundary talk takes place in the spaces provided by the $\mathrm{CiC}, \mathrm{CiD}$ and $\mathrm{CfT}$, as students explore how their substantial and situational identities intersect with the human right to gender equality. By doing so, the possibility exists for transdisciplinary restorying to take place, and this has the potential to contribute to social transformation.

\section{Methodology}

This small-scale project employed a narrative research design, conducive to the exploration of the ways in which the student participants construct, interpret and give meaning to their subjective experiences with regard to gender equality. 
It also provided the space to describe and explore how people are similar to and also different from one another (Newman 2011; Silverman 2010).

Narrative inquiry as a methodology within narrative research (Chase 2011; Clandinin 2007; Clandinin et al. 2010; Luttrell 2010; Riessman 2008; Squire, Andrews \& Tamboukou 2008), and with a strong representation in the field of education (Clandinin 2007), refers to 'the authentic accounts of real life experiences' (Nothling 2001:153). Squire et al. (2008:4) add to this idea of narrative contending that it is 'always multiple, socially constructed and constructing, reinterpreted and reinterpretable'. Narratives can be used to maintain the status quo but can also have an emancipatory function, transforming individual lives and the broader culture (Plummer 1995).

\section{Participants}

Twenty-four Social Sciences Honours students representing nine disciplines within the Social Sciences cluster agreed to participate in this project. It so happened that there were 12 men and 12 women, ranging from their mid-20s to 50 years of age and Black African in the main. Participants signed consent forms, including permission for the CiD and CfT to be audio recorded. They were assured that their anonymity would be protected and that pseudonyms would be used when citing their responses.

\section{Empathetic-Reflective-Dialogical Restorying}

The particular Honours module focused on various components of research. Students were tasked with choosing a particular topic from a broad list of topics related to Social Sciences including issues related to human rights. They read about their topic, or a particular aspect thereof, presented their substantiated perspectives to the class, and submitted an annotated bibliography. Students were then required to design a mini-proposal for a small-scale project further researching the topic presented in class. The literature review constituted a separate assignment for assessment. In a discussion about research methodologies, EmpatheticReflective-Dialogical Restorying served as a demonstration of a data collection method. It was also introduced to facilitate transdisciplinary boundary talk. The students would be required to evaluate the efficacy of this particular method of data collection for the possible transformation of attitudes towards gender equality and for better understandings of the other in society. The researcher explained to the students that while Empathetic-Reflective-Dialogical Restorying can be used to engage in transdisciplinary boundary talk focusing on numerous human rights issues, for the purposes of this project, it would be used to explore how the substantial and situational identities of the participating Social Sciences students intersect with the human right to gender equality. Their self-dialogue and self-narrative contributed to their engagement in a $\mathrm{CiC}, \mathrm{CiD}$ and $\mathrm{CfT}$. The researcher explained the process, locating it within the theoretical framework outlined previously. She introduced and asked the participants to consider three questions at levels 1 and 2. A female and a male participant were asked to each lead a separate $\mathrm{CiC}$ on level 3. Levels 4 and 5 were guided by the researcher and audio recorded. Table 1 presents these five levels and what transpires in respect of each.

On level one, the Social Sciences participants were given the opportunity to consider the dominant individual and collective voices informing the internal $I$ positions which they hold in their society-of-mind with regard to the position of men and women in their religious or cultural discourses. They were asked to consider the following questions:

1. Gender equality has been defined by Subrahmanian (2005) as men and women being equal to one another in quality, and identical in value, with men and women having the same rights and opportunities. Do you think your religious or cultural identities affect the way in which you view the human right to gender equality? Please explain.

2. What does your religion or culture say about your position as a man or as a woman?

3. What does your religion or culture say about your role and responsibilities as a man/as a woman?

It was on this level that the participants negotiated their selfdialogue and considered or adopted counter positions to male hegemony as they engaged their dialogical self in action (Hermans \& Hermans-Konopka 2010). Their self-dialogue found expression in level two where they wrote their selfnarratives.

At level two the Social Sciences participants, both men and women, in response to the above questions, were required to write their self-narrative. According to Gonçalves and Ribeiro (2012:302), this self-narrative was the outcome of dialogical processes of negotiation, tension, disagreement, alliance and so on, between different voices of the self'. The self-narrative, writing for the self (Ellis 2004), could be therapeutic as it

TABLE 1: Empathetic-Reflective-Dialogical Restorying - Five levels.

\begin{tabular}{|c|c|c|c|}
\hline Levels & Process & Audience & Result \\
\hline 1 & - Self-dialogue & $\begin{array}{l}\text { Society-of-mind } \\
\text { Internal audience }\end{array}$ & $\begin{array}{l}\text { Negotiation of } \\
\text { various/positions } \\
\text { and re-positioning } \\
\text { of voices in the } \\
\text { society-of-mind }\end{array}$ \\
\hline 2 & $\begin{array}{l}\text { - Self-narrative } \\
\text { written text }\end{array}$ & $\begin{array}{l}\text { Male and female Social Sciences } \\
\text { participants }\end{array}$ & $\begin{array}{l}\text { Production of own } \\
\text { meaning and } \\
\text { knowledge }\end{array}$ \\
\hline 3 & $\begin{array}{l}\text { - Self-narrative } \\
\text { shared with an } \\
\text { external audience } \\
\text { - Communities in } \\
\text { conversation (CiC) }\end{array}$ & $\begin{array}{l}\text { External audience } \\
\text { At this level, male and female } \\
\text { Social Sciences participants were } \\
\text { separated and in a CiC they } \\
\text { shared their self-narratives } \\
\text { exchanging perspectives and } \\
\text { personal experiences in a space } \\
\text { comprising their own gender }\end{array}$ & $\begin{array}{l}\text { Co-production with } \\
\text { writers/storytellers }\end{array}$ \\
\hline 4 & $\begin{array}{l}\text { - Self-narrative } \\
\text { shared with an } \\
\text { external audience } \\
\text { - Community in } \\
\text { dialogue (CiD) }\end{array}$ & $\begin{array}{l}\text { External audience } \\
\text { At this level, male and female } \\
\text { Social Sciences participants } \\
\text { shared their self-narratives with } \\
\text { one another }\end{array}$ & $\begin{array}{l}\text { Co-production with } \\
\text { writers/storytellers }\end{array}$ \\
\hline 5 & $\begin{array}{l}\text { - Group narrative } \\
\text { - Community for } \\
\text { transformation } \\
\text { (CfT) }\end{array}$ & $\begin{array}{l}\text { External audience. } \\
\text { Male and female Social Sciences } \\
\text { participants }\end{array}$ & $\begin{array}{l}\text { Co-production of } \\
\text { possible new } \\
\text { narrative for } \\
\text { transformation }\end{array}$ \\
\hline
\end{tabular}


caused the participants to pause and to think about their positionality in relation to gender equality. This could also be empowering as their writing exposed a new sense of consciousness and a greater sense of control in the present and for the future (Paul, Christensen \& Frank 2000).

At level three, the Social Sciences participants were separated into two groups, one for the men and the other for the women. In each group or $\mathrm{CiC}$, they were afforded the opportunity to share their written reflections orally in response to the questions below. Sharing their self-narratives provided the opportunity for them to individuate as 'equal ... dignified partner[s] in constituting reality and constructing the world' (Becker 2012:89):

1. What does your religion or culture, which informs your substantial identity, say about your position and roles and responsibilities as a man or as a woman?

2. What does your religion or culture say about possible privileges that you have as a man or as a woman in your personal, social and professional domains?

3. What does your religion or culture say about possible expectations of men or of women in their personal, social and professional domains?

At level four, the Social Sciences students together entered into a CiD. This fostered the opportunity in which the other was disclosed to their other (women or men) in a dialogue which included a rhetoric that questioned and a rhetoric that inspired reciprocal exchanges with tolerant and empathetic understanding. The researcher facilitated the responses of the participants who were asked to discuss their responses from the $\mathrm{CiC}$ with their other (women or men), using the following headings:

1. Gender-based roles and responsibilities.

2. Gender-based privileges.

3. Gender-based expectations of the other.

4. Religious and/or cultural understandings of the position of men and women and the possible impact of this on the way in which gender equality would be approached in their professional spaces.

At level five, a whole group discussion as a CfT took place with the aim of exploring how their substantial identities and substantial attitudes towards gender equality informed their situational or professional practice. This constructive engagement had the potential to lead to new layers of consciousness (Ritchie \& Wilson 2000; White 2012) as participants considered self-respect and own positionality and inspired reciprocal exchanges with empathetic understanding. This had the potential to lead to the emergence of collaborative initiatives for negotiating entrenched positions disentanglement from their other and restorying for transformation.

The researcher guided the discussion at level five with the following questions:

1. How has Empathetic-Reflective-Dialogical Restorying impacted your understanding of gender equality in terms of experiences, roles and responsibilities, privileges and expectations?

2. How has the dialogue impacted on your perspectives of teaching-learning about gender issues and promoting gender equality?

3. Evaluate the efficacy of Empathetic-Reflective-Dialogical Restorying for the transformation of attitudes towards gender equality and for better understandings of the other in society.

\section{Analysis}

Drawing on the work of various scholars (Chase 2011; Gubrium \& Holstein 2009; Luttrell 2010; Silverman 2010), narrative analysis was employed as a means of analysis. All five levels of Empathetic-Reflective-Dialogical Restorying are implicit in the discussion which follows. The written responses (level 2) and audio recorded conversations at levels 4 and 5 were crystallised (Maree 2007) to lend authenticity (Newman 2011). The dissonance between the participants' substantial and situational identities with regard to gender equality became very apparent.

The engagement with the different levels of EmpatheticReflective-Dialogical Restorying increased levels of trust between the participants, 'blurring the disciplinary boundaries and escalating valuing of each other's knowledge and perspectives ... working for a common cause' (McGregor \& Volckmann 2013:61), in this case engaging with their understandings of the human right to gender equality.

Various threads emerged from the transdisciplinary boundary talk focusing on how the situational and substantial identities of the participants intersect with the human right to gender equality.

\section{Dissonance, as substantial identity intersects with the human right to gender equality}

Postgraduate students who are aspiring academics have cognitive understanding of Human Rights Education and the South African Bill of Rights. However, there is a dissonance between the demands placed by this understanding on their situational identity as professionals and their substantial identity as informed by their religion or culture. Their selfdialogue is informed by both individual and collective dominant voices reinforcing entrenched attitudes of male hegemony. This finds its way into their written selfnarratives as shared in the $\mathrm{CiC}$ and discussed with their other in the CiD.

Gender-based roles, expectations and responsibilities are deeply entrenched. The man is acknowledged as the provider, controller of finances, head of the family and the protector of the family. He is seen as superior to women and deserving of privileges. What follows is a selection of comments, illustrating the firmly held position of gender inequality. 
The man is the head of the home:

'The man is head of family, a provider, a protector, a decision maker.' (Themba, male, student)

'The men should run the finances ... the man is in control ... if wife earns more than you then you are discredited and women look down on you if you earn less.' (Sabelo, male, student)

'A man should be strong, he does not cry, but only cries on the inside.' (Patrick, male, student)

Men are entitled to privileges:

'The man is the provider and the one taking the major role in making decisions ... and he has privileges.' (Dumi, male, student)

Dumi provides the following elucidation of these privileges:

Whenever I come back home they [women] have to wash for me cook for me ... do everything for me ... sometimes even the career women will come and cook for me because being a man is a privilege ... getting a family name ... also in religion whenever she is ... she will have to come to me [to my religion] ... and also [take my] family name. (Dumi, male, student)

These privileges include an entitlement to the lion's share in any inheritance.

Michael expresses this when he says:

'.... as a man you need to take over the cows and everything, they belong to you.' (Michael, male, student)

Men must marry. It is considered a good thing for a man to be married and to have many women:

You have to be married ... if not married you are considered to be a boy ... you are regarded as a man if you have many children even if outside the marriage.' (Muntu, male student)

'... the more girlfriends they have the more of a man they are ... even given different names if you have one woman or more than one.' (Phumi, female student)

Men expect women to be submissive to them:

'The woman needs to be submissive to me ... there is a logic in this ... because I do everything for [her]'. (Muntu, male student)

'The man is the head and the woman the Helper ... the man is the head of a woman ... and the responsibility of a woman is to be submitted under the authority of the man.' (Ayanda, female, student)

Nomsa describes this submission as follows:

'... serving the man constantly, cooking for him, looking after the house ... he has to go out to work ... the male is the head of the family and we [the women] have to do everything that he says.' (Nomsa, female, student)

Men are superior to women. It became apparent that from childhood gender inequality is taught, and more specifically, that women are less than men:

'As I was growing up I was taught that men and women cannot have the same value. Men should be valued the most important because they are the head of the house or family ...' (Thula, female, student)
'My position as a man in my culture certainly comes first than that of a woman. Men make the decisions and also enforce these decisions.' (Muntu, male, student)

'Women and men are not viewed in the same way. Men are seen as superior while women are seen as inferior.' (Mary, female, student)

It is clear from the above extracts that entrenched in the participants' substantial identities as experienced in their culture or religion is the notion that men are superior to women and this creates a dissonance with their situational identities as professional teachers. This highlights the need for the provision of intervention strategies in their graduate programmes to enable students to engage with, and negotiate, dissonances between their substantial and situational identities.

\section{The need for the other to listen to his or her other (women or men)}

The interaction in the CiD (level 4) highlighted the dissonance between human rights and substantial identity. In a safe space created both physically and figuratively, men and women listened to their other (women or men). For some like Majozi, the very notion of gender equality is offensive. For others like Alex, while they aspire to embrace gender equality, they encounter difficulties in doing so. Alex provided the following example:

Although I am a modern man with a broader understanding of the world I still find myself not seeing genders being equal. For example, if I come home and have to serve a plate and there are elders that consist of male and female, my cultural identity tells me to serve the male elders first although in my view it should be equal but it is not ... and if I served women first at home, the women will probably pass the plates to the men to eat first so even when I try to practice equality my society doesn't allow me. (Alex, male, student)

The women agreed this was the case because of the entrenched gender attitudes in their religion or culture that men are superior and should be served and that they deserve to have many privileges. By contrast the women reflected that they do not have any privileges:

'We don't have much privileges ... all in all we don't ... as men do.' (Phumi, female, student)

Precious challenged her other (men) saying that she should have a voice in her home, but on the contrary, she has no voice in her family:

'The voice of a man is the one that will be listened to ... women should respect men while men does not teach the respect for their wife, they even beat them or abuse them, therefore the human right to gender equality has been violated because we are not getting the same treatment as the man.' (Precious, female, student)

Ncami and Lindi expressed their frustration in knowing that they have legal equal gender rights but only in theory.

'I believe in equality ... although until this day there is still no gender equality. Men are still regarded to be superior to women.' (Ncami, female, student) 
'In theory we have equal rights but in practice I am still reminded that I am female and there are certain things that I still cannot do.' (Lindi, female, student)

Thabi disagreed with her other (men) that it is considered as acceptable for a man to be married and to have girlfriends. She says:

'As a woman I expect that my husband will have one wife ... as a woman I am expected to be only one'. (Thabi, female, student)

Two of the men in the group challenged the culturally entrenched social construct of women being less than men and having to always serve the men. Their households, in contrast to others, did not promote gender-specific roles.

'... if my wife is tired I will cook'. (Thabo, male, student)

'Where I come from (my home) there are no specific roles that a male should play and a female should not. I did all and I am still doing the house duties with my sister ... we do things collectively as our parents told us there is no male and female, cook if you have to and clean the yard if you want to regardless of your gender. (Nkosi, male, student)

The CiD provided the opportunity for the participants to engage with one another in a safe space and to challenge gender inequality and to explore how attitudes and positions shaping substantial identities are socially constructed. The dialogue was not bound by a particular academic discipline but rather the boundary talk was robust, rigorous and transdisciplinary.

\section{Efficacy of Empathetic-Reflective-Dialogical Restorying}

At level 5, discussing the possibilities of transdisciplinary restorying, participants suggested that a possible limitation could be that this teaching-learning strategy 'needs willing participants' and could possibly not be effective with a group 'who don't really care' (Zanele) or who are unwilling to participate in any boundary talk.

A unanimous show of hands indicted that the participants in this project, having participated in Empathetic-ReflectiveDialogical Restorying were far more aware of their selfdialogue (level 1) and the dominant voices in their society-ofmind which impacted their self-narratives (level 2). They were also sensitised to the possibilities of their dialogical self in action as they adopted counter positions to dominant voices in their society-of-mind.

The participants said that they appreciated the opportunity to share their self-narratives with one another in a CiC (level 3).

'... very impactful ... I thought I understood gender equality but in CiC made aware of our privileges as men ... we have a lot of privileges we are not aware of.' (Dumi, male, student)

The CiD (level 4) provided the opportunity for the men or women to listen to their other (women or men):

'... the best part was when the other participant says how she really feels about my experience ... this puts emphasis on how does the other party feel about my actions ... appeals to feelings ... then you think about it more.' (Sabelo, male, student)

The dissonance between human rights as it relates to gender equality and the implementation thereof at the intersection with substantial identities became very clear in the discussion.

The CfT (level 5) provided the opportunity to think critically about processes of socialisation into societal norms with regard to gender issues, such as that of patriarchy, and to discuss and begin the process of deconstructing the same. The disjuncture between substantial and situational identities was unpacked. Participants were made aware of how their substantial identities impact their situational identities and the expectations of them as professionals to implement gender equality. Thabo expressed the opinion of the majority of the participants when he said: 'if we can't do that then how are we going to be instrumental in transforming society?'

The participants were seemingly of the opinion that Empathetic-Reflective-Dialogical Restorying provided the opportunity to engage meaningfully with issues of substantial identity and the human right to gender equality across disciplinary boundaries:

'I think this strategy gives out many possible ideas to think critically ... what can we do ... what are the gaps ... what can be changed.' (Phumi, female, student)

'I think it gives you a better understanding of ... all the issues.' (Thabi, female, student)

'This strategy is transformative ... some will actually go home today and some have daughters and some have sons and will try and change things.' (Ncami, female, student)

Participants suggested that while, in this study, EmpatheticReflective-Dialogical Restorying focused on the human right to gender equality as the topic for transdisciplinary boundary talk, this teaching-learning strategy could be employed to engage in transdisciplinary boundary talk about various other human rights issues such as racism, xenophobia and so forth. The constant aim would be that of bringing about social transformation as participants engage meaningfully with their internal audiences (self-dialogue) and external audiences. The suggestion was made that EmpatheticReflective-Dialogical Restorying could be used in various contexts such as parliament, for politicians to engage meaningfully, considering their own self-dialogue and selfnarrative and that of the other, so as to engage in conversation and dialogue in order to forge a way forward that is transformative for society.

The participants were in agreement that this teachinglearning strategy provided a way in which to create cohesion among the multiple disciplines embedded within the Social Sciences.

\section{Conclusion}

Faculties and School's of Education are professionally bound to provide intervention strategies in their graduate 
programmes to enable students to engage in transdisciplinary boundary talk which can contribute to social transformation (Hampson \& Assenza 2012). Academics engaging with transdisciplinary work will strive to 'fuse perspectives' (McGregor \& Volckmann 2013:62) to generatenew knowledges.

This article shows how Empathetic-Reflective-Dialogical Restorying fuses perspectives and generates new knowledges that cross disciplinary boundaries. Self-dialogue and selfnarrative communicated in a safe space within a $\mathrm{CiC}, \mathrm{CiD}$ and CfT is not discipline bound. It is empathetic, reflective and dialogical, engaging with the intersection between substantial and situational identities and human rights issues. This process requires the ability to see the world through the lens of others ... providing space within which to grow peoples' capacity to communicate across boundaries' (McGregor \& Volckmann 2013:62-63).

Empathetic-Reflective-Dialogical Restorying as a teachinglearning strategy facilitates the nudging of static disciplinary boundaries within the Social Sciences and creates open spaces for empathetic, reflective dialogue that carries the potential of generating new transdisciplinary knowledges in the space between, across and beyond academic disciplines. In this case, the intersection of substantial and situational identities and the human right to gender equality was explored. Transdisciplinary engagement, as reflected in this article in Empathetic-Reflective-Dialogical Restorying, could create cohesion among the multiple disciplines embedded within the Social Sciences and has the potential to be socially transformative.

\section{Acknowledgements}

The ethical code of conduct and requirements set for narrative research by the tertiary institution's ethics committee were adhered to in conducting this study.

\section{Competing interests}

The author declares that she has no financial or personal relationships which may have inappropriately influenced her in writing this article.

\section{References}

Abdool, D. \& Drinkwater, M., 2005, 'Guidelines to create a positive classroom climate for Religion Education: An empathetic approach', Scriptura 89, 363-372. https:// doi.org/10.7833/89-0-1023

Allen, L., 2004, 'From votes to dialogues: Clarifying the role of teachers' voices in School Renewal', Phi Delta Kappan 218-321. https://doi.org/10.1177/ 003172170408600416

Becker, A., 2012, 'Identity premised on equality of difference as a fundamental human right', in C. Roux (ed.), Safe spaces: Human rights education in diverse contexts, right', in C. Roux (ed.), Safe spaces: Hum
pp. 83-96, Sense Publishers, Rotterdam.

Chase, S., 2011, 'Narrative inquiry: Still a field in the making', in N. Denzin \& Y. Lincoln (eds.), The Sage handbook of qualitative research, pp. 421-434, Sage, London.

Clandinin, D.J., 2007, Handbook of narrative inquiry: Mapping a methodology, Sage Thousand Oaks, CA.

Clandinin, D.J., Murphy, M.S., Huber, J. \& Orr, A.M., 2010, 'Negotiating narrative inquiries: Living in a tension-filled midst', Journal of Educational Research 103 81-90. https://doi.org/10.1080/00220670903323404

Crenshaw, K., 2003, 'Mapping the margins: Intersectionality, identity politics and violence against women of colour', in L. Alcoff \& E. Mendieta (eds.), Identities: Race, class, gender and nationality, pp. 175-200, Blackwell Publishers, Malden, MA.
De Wet, A. \& Parker, G., 2014, 'Communities in conversation: Opportunities for women and girls' Self-empowerment', Gender and Development 22, 109-125. https://doi.org/10.1080/13552074.2014.889341

Department of Education, 2001, Manifesto on values, education and democracy, Government Printers, Pretoria.

Department of Education, 2003, Policy of human rights across the curriculum, Government Printers, Pretoria.

Du Preez, P., 2013, 'A human rights based curriculum for religious schools: The responsibilities of school leaders', in M. Buchanan (ed.), Leadership \& religious schools: International perspectives and challenges, pp. 53-67, Bloomsbury, New York.

Du Preez, P. \& Simmonds, S., 2011, 'Understanding how we understand girls' voices on cultural and religious practices: Toward a curriculum for justice', South African Journal of Education 31, 322-332. https://doi.org/10.15700/saje.v31n3a536

Ellis, C., 2004, The ethnographic I: A methodological novel about autoethnography, AltaMira Creek, Walnut Creek, CA.

Godemann, J., 2006, 'Promotion of interdisciplinary competence as a challenge for higher education', Journal of Social Science Education 5(2), 51-61.

Gonçalves, M. \& Ribeiro, A., 2012, 'Narrative processes of innovation and stability within the dialogical self', in H. Hermans \& T. Gieser (eds.), Handbook of dialogical self theory, pp. 301-308, Cambridge University Press, Cambridge, UK.

Green, J., 1999, Deep democracy: Community, diversity and transformation, Rowan \& Littlefield, Oxford, England.

Gubrium, J. \& Holstein, J., 2009, Analyzing narrative reality, Sage, Thousand Oaks, CA.

Hampson, G. \& Assenza, G., 2012, Transformative higher education for humanity and biosphere: An introduction, School for Transformative Leadership, Olomouc, Czech Republic

Hermans, H., 2011, 'The dialogical self: A process of positioning in space and time', in S. Gallagher (ed.), The Oxford Handbook of the Self, pp. 654-680, Oxford University Press, Oxford, UK.

Hermans, H. \& Hermans-Konopka, A., 2010, Dialogical self theory: Positioning and counter-positioning in a globalizing society, Cambridge University Press, Cambridge, UK.

Ipgrave, J., 2003, 'Dialogue, citizenship and religious education', in R. Jackson (ed.), International perspectives on citizenship, education and religious diversity, pp. 147-168, RoutledgeFalmer, London.

Jacobs, M., Vakalisa, N. \& Gawe, N., 2011, Teaching-Learning Dynamics, Pearson Education, Cape Town, South Africa.

Jarvis, J., 2013, 'Female Teachers' religious and cultural identities and gender equality', $\mathrm{PhD}$ thesis, North West University, Potchefstroom.

Lawler, S., 2008, Identity: Sociological perspectives, Polity Press, Cambridge.

Luttrell, W., 2010, Qualitative educational research, Routledge, New York \& London.

Maree, K., 2007, First steps in research, Van Schaik, Pretoria.

McCormack, C. \& Kennelly, R., 2011, 'We must get together and really talk ...' Connection, engagement and safety sustain learning and teaching conversation communities', Reflective Practice 12(4), 515-531. https://doi.org/10.1080/14623 communities', Reflect

McGregor, S.L.T., 2011, 'Demystifying transdisciplinary ontology: Multiple levels of reality and the hidden third' Integral Leadership Review 11(2), viewed 28 September 2017, from http://integralleadershipreview.com/1746-demystifying-

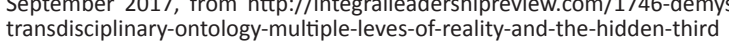

McGregor, S.L.T. \& Volckmann, R., 2013, 'Transversity: Transdisciplinarity in higher education', in G. Hampson \& M. ih-Tolsma (eds.), Leading transformative higher education, Palacky University Press, Olomouc, Czech Republic.

Newman, W., 2011, Social research methods, Pearson, New York.

Nias, J., 1989, Primary teachers talking: A study of teaching as work, Falmer Press, London.

Nicolescu, B., 2005, 'Towards transdisciplinary education', The Journal of Transdisciplinary Research in Southern Africa 1(1), 5-16. https://doi.org/10.4102/ td.v1i1.300

Nicolescu, B., 2012, Transdisciplinarity and sustainability, TheAtlas Publishing, Austin, TX.

Nicolescu, B., 2014, 'Methodology of transdisciplinarity', World Futures 70, 189-199. https://doi.org/10.1080/02604027.2014.934631

Nothling, M., 2001, 'Telling our stories-feeling our pain: Designing a transformational human rights course', in F. Swanepoel (ed.), Religion and morality transformation, pp. 134-168, University of South Africa, Pretoria.

Nuttall, S., 2009, Entanglement: Literary and cultural reflections on post-apartheid, Wits University Press, Witwatersrand.

Paul, J., Christensen, L. \& Frank, G., 2000, 'Accessing the intimate spaces of life in the classroom through letters to former teachers: A protocol for uncovering hidden stories', in J. Paul \& T. Smith (eds.), Stories out of school: Memories and reflection on care and cruelty in the classroom, Ablex publishing Corporation, Stanford, CT.

Petts, J., Owens, S. \& Bulkeley, H., 2008, 'Crossing boundaries: Interdisciplinarity in the context of urban environments', Geoforum 39, 593-601. https://doi. org/10.1016/j.geoforum.2006.02.008

Plummer, K., 1995, Telling sexual stories, Routledge, London.

Redmond, M., 2010, 'Safe space oddity: Revisiting critical pedagogy', Journal of Teaching in Social Work 30, 1-14. https://doi.org/10.1080/08841230903249729 
Republic of South Africa, 1996, The bill of rights: Chapter 2 of the constitution of the Republic of South Africa, Government Printers, Cape Town.

Riessman, C.K., 2008, Narrative methods for the human sciences, Sage, Los Angeles, CA.

Ritchie, J. \& Wilson, D., 2000, Teacher narrative as critical inquiry: Rewriting the script, Teacher's College Press Columbia University, New York.

Roux, C., 2012, 'A social justice and human rights education project: A search for caring and safe spaces', in C. Roux (ed.), Safe spaces: Human rights education in diverse contexts, Sense Publishers, Rotterdam.

Shields, S., 2008, 'Gender: An intersectionality perspective', Sex Roles 59, 301-311. https://doi.org/10.1007/s11199-008-9501-8

Silverman, D., 2010, Doing qualitative research, Sage, Los Angeles, CA.

Simmonds, S. \& Du Preez, P., 2017, 'Discourses shaping human rights education research in South Africa: Future considerations', South African Journal of Higher Education 31(6), 9-24. https://doi.org/10.20853/31-6-1635
Squire, C., Andrews, M. \& Tamboukou, M., 2008, 'What is narrative research?', in M. Andrews, C. Squire \& M. Tamboukou (eds.), Doing narrative research, pp. 1-26, Sage, London.

Stengel, B. \& Weems, L., 2010, 'Questioning safe space: An introduction', Studies in Philosophy of Education 29, 505-507. https://doi.org/10.1007/s11217-0109205-8

Subrahmanian, R., 2005, 'Gender equality in education: Definitions and measurements', International Journal of Educational Development 25, 395-407. https://doi.org/10.1016/j.ijedudev.2005.04.003

Ter Avest, I., 2011, Voices: Beyond the confusion of the encounter with the other, Hogeschool INHolland, Utrecht.

Wetherell, M., 1996, 'Life histories/Social histories', in M. Wetherell (ed.), Identities, groups and social issues, pp. 299-342, Sage, Thousand Oaks, CA.

White, E., 2012, Whiteness and teacher education, Routledge, New York and London. 